\title{
Subluxed traumatic cataract: optical coherence tomography findings and clinical management
}

This article was published in the following Dove Press journal:

Clinical Ophthalmology

3 December 2012

Number of times this article has been viewed

\section{Ajay E Kuriyan \\ Harry W Flynn Jr \\ Sonia $\mathrm{H}$ Yoo}

Department of Ophthalmology,

Bascom Palmer Eye Institute,

University of Miami, Miami, FL, USA
Correspondence: Ajay Kuriyan

900 NW 17th Street, Miami,

FL 33136, USA

$\mathrm{Tel}+\mathrm{I} 3053266000$

Fax +I 3053266417

Email akuriyan@med.miami.edu
Abstract: This case report describes the optical coherence tomography (OCT) findings and clinical management of a patient with traumatic subluxed cataract. The patient presented with a traumatic subluxed cataract and vitreous prolapse into the anterior chamber. The anterior segment OCT showed vacuoles in the anterior subcapsular regions of the crystalline lens. The patient was treated with pars plana lensectomy, vitrectomy, and placement of an anterior chamber intraocular lens. The patient's best corrected visual acuity improved from hand motion at presentation to 20/25 during 3 years of follow-up. Anterior segment OCT demonstrates that the clinically visible vacuoles in traumatic cataract are located in the anterior subcapsular part of the lens. This is the first report in the literature using anterior segment OCT to visualize the subcapsular vacuolar changes in a traumatic cataract.

Keywords: traumatic cataract, subluxed lens, vacuoles, anterior chamber intraocular lens, anterior segment optical coherence tomography

\section{Introduction}

Approximately $30 \%$ of serious eye injuries in the US involve damage to the lens. ${ }^{1}$ Traumatic lenticular damage can include subluxation, dislocation, disruption of the lens capsule, zonular weakness, and cataract formation. ${ }^{1,2}$ Closed-globe traumatic cataracts have been divided into two subtypes, ie, immediate onset or delayed onset, based on the time between the initial trauma and presentation with a symptomatic cataract. $^{2}$ Traumatic lens subluxation or dislocation occurs in blunt trauma as a result of equatorial stretching and rupture of zonules. ${ }^{3}$ Traumatic equatorial stretching can also result in disruption of the anterior hyaloid face and vitreous prolapse into the anterior chamber. ${ }^{3}$ Anterior segment optical coherence tomography (OCT) can be utilized to identify traumatic damage to the lens capsule, cortex, and zonules. ${ }^{4}$ This is the first report in the literature using anterior segment OCT to demonstrate anterior subcapsular vacuoles in a traumatic cataract. In this case report, we describe the management, outcome, and anterior segment OCT findings of a patient with a traumatic, subluxed cataract.

\section{Case report}

A 59-year-old male was referred for evaluation and management of a traumatic, subluxed cataract in his left eye. The patient was struck in his left eye by a full can of beer 8 months earlier and developed inferior temporal subluxation of his crystalline lens. After the accident, he developed progressive loss of vision in the left eye as his lens became more cataractous. At presentation, he was noted to have a best-corrected visual acuity (BCVA) 
of 20/20 in his right eye and hand motion vision in his left eye. His intraocular pressure was $15 \mathrm{mmHg}$ in his right eye and $18 \mathrm{mmHg}$ in his left eye. His pupils were symmetric and he did not have an afferent pupillary defect. His right eye anterior examination revealed a $1^{+}$nuclear sclerotic cataract and the posterior segment examination was normal. His left anterior segment was significant for an inferiorly and temporally subluxed opaque lens with vacuolar changes (Figure 1A). Superior nasal vitreous prolapse was also noted in the anterior chamber and around the superior pole of the crystalline lens (Figure 1B). The patient was also noted to have angle recession from 10 o'clock superiorly to 3 o'clock. A red reflex was present in the left eye but there was no view of the fundus details through the densely opaque lens. Ultrasonography of the left eye demonstrated mild vitreous opacities with a posterior vitreous detachment and a posterior staphyloma. Anterior segment OCT was performed using the Visante ${ }^{\mathrm{TM}}$ OCT Model 1000 (Carl-Zeiss Meditec, Dublin, CA), which has an axial resolution of $18 \mu \mathrm{m}$, and revealed an intact anterior lens capsule and subcapsular vacuolar changes (Figure 2).
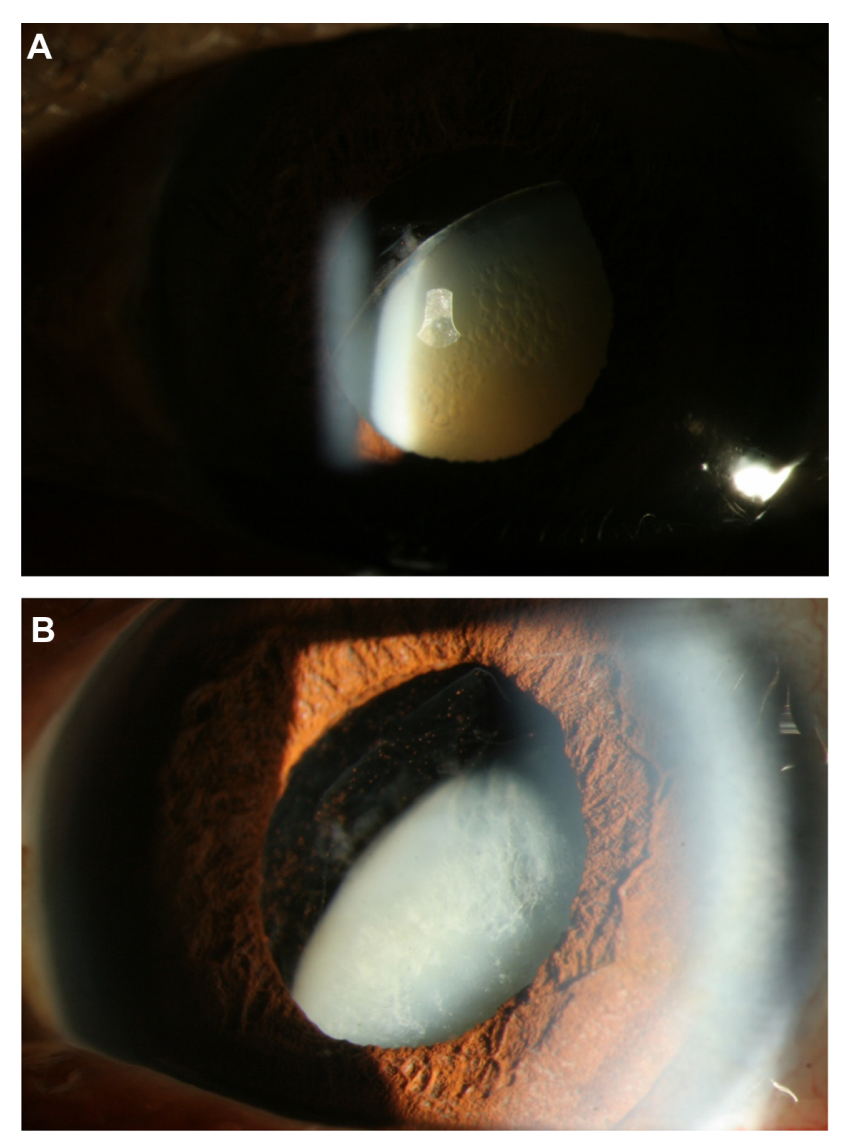

Figure I (A) Slit lamp photograph of the left eye with anterior subcapsular vacuolar changes in a subluxed cataractous crystalline lens. (B) Slit lamp photograph of the left eye with subluxed crystalline lens and vitreous prolapse into the anterior chamber.
After a discussion of all management options, a decision was made for surgery. The patient underwent pars plana lensectomy, vitrectomy, anterior chamber intraocular lens (AC-IOL) placement, and superior peripheral iridotomy. An AC-IOL was placed due to inadequate lens capsule support secondary to severe traumatic zonular damage. On the first postoperative day, the patient was found to have a BCVA of $20 / 70^{+2}$ in the left eye with an intraocular pressure of $15 \mathrm{mmHg}$. The anterior segment examination revealed a well-centered AC-IOL with a patent superior peripheral iridotomy. The posterior segment examination showed a normal optic disc, macula, and periphery. Although a staphyloma was detected on ultrasonography, it was not appreciated on examination. At the 3-month postoperative visit, the patient's left eye BCVA was 20/30 and intraocular pressure was $13 \mathrm{mmHg}$. The patient's BCVA improved to 20/25 in the left eye at the 9-month postoperative visit and has remained stable as of his most recent visit at 34 months after surgery.

\section{Discussion}

The unique features of this case report are the striking lens abnormalities and their corresponding OCT findings. This is the first report in the literature using anterior segment OCT to visualize the traumatic subcapsular vacuolar changes in a traumatic cataract. The subcapsular vacuolar changes observed in this case are due to intracellular spaces in the cataractous lens. ${ }^{5}$ Subcapsular changes analogous to the OCT findings in our patient have been identified using electron microscopy in a rat cataract model. ${ }^{5}$

The integrity of the lens capsule and zonules dictate the location of the IOL placement. While our patient had clinically apparent disruption of zonules, this is not always the case in traumatic cataracts. Anterior segment OCT can be utilized in such cases to identify damage to the lens capsule and/or zonules. Patients with an anterior segment OCT demonstrating an intact lens capsule with localized zonular weakness may be amenable to placement of the IOL within the capsular bag with the haptics positioned perpendicular to the area of zonular weakness or with utilization of a capsular tension ring. ${ }^{3,6}$ Patients with an unstable or ruptured lens capsule on OCT may require placement of the IOL into the sulcus or anterior chamber. ${ }^{3,6}$ The use of AC-IOL can be considered in patients with good iris support, absence of advanced glaucoma, and in adult patients..$^{3,6}$ The alternative to AC-IOL placement is iris, trans-scleral, or scleral pocket suture fixation., ${ }^{3,6,7}$ 


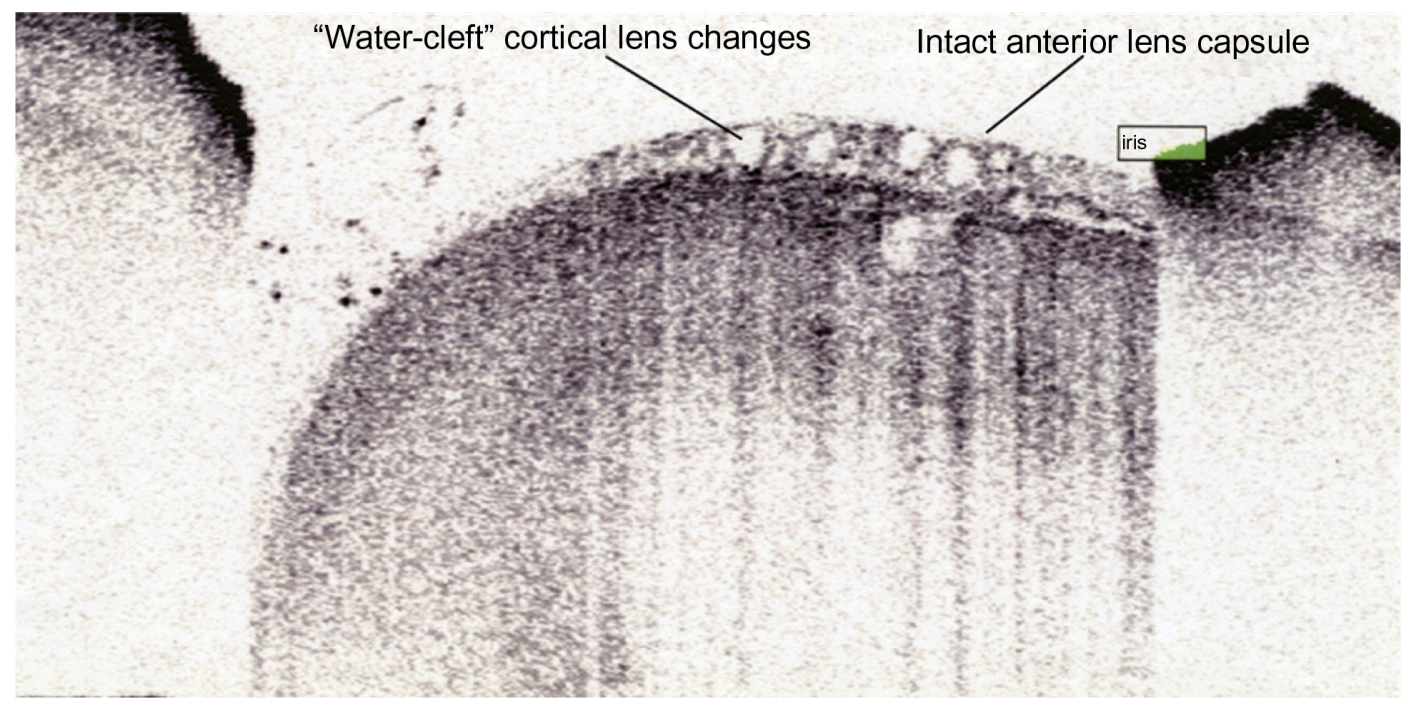

Figure 2 Visante ${ }^{\mathrm{TM}}$ anterior segment optical coherence tomographic image demonstrating an intact anterior lens capsule and anterior subcapsular vacuolar cataractous changes.

Note: The anterior lens capsule appears to be intact.

\section{Conclusion}

Assessment of the lens capsule, vitreous prolapse, and zonular integrity are essential in guiding management of traumatic cataracts. Anterior segment OCT is a new adjunctive tool for assessing lens capsule and zonular integrity and intralenticular changes. Pars plana lensectomy with vitrectomy and AC-IOL placement can effectively restore vision in patients with traumatic subluxed cataracts and vitreous prolapse.

\section{Disclosure}

HWF is a consultant for Alimira, Pfizer, and Santen. SHY is a consultant for Alcon, Bausch and Lomb, Carl Zeiss Meditec, Optimedica, and Transcend Medical, and has received research grants from Genentech and Allergan. AEK discloses no conflicts of interest in this paper.

\section{References}

1. Kuhn F, Morris R, Witherspoon CD, et al. Epidemiology of blinding trauma in the United States eye injury registry. Ophthalmic Epidemiol. 2006;13:209-216.

2. Greven CM, Collins AS, Slusher MM, et al. Visual results, prognostic indicators, and posterior segment findings following surgery for cataract/ lens subluxation-dislocation secondary to ocular contusion injuries. Retina. 2002;22:575-580.

3. Mian SI, Azar DT, Colby K. Management of traumatic cataracts. Int Ophthalmol Clin. 2002;42:23-31.

4. Sarunic MV, Asrani S, Izatt JA. Imaging the ocular anterior segment with real-time, full-range fourier-domain optical coherence tomography. Arch Ophthalmol. 2008;126:537-542.

5. Kuwabara T, Kinoshita JH, Cogan DG. Electron microscopic study of galactose-induced cataract. Invest Ophthalmol Vis Sci. 1969;2:133-149.

6. Kwitko ML, Kwitko GM. Management of the traumatic cataract. Curr Opin Ophthalmol. 1990;1:25-27.

7. Hoffman RS, Fine IH, Packer M. Scleral fixation without conjunctival dissection. J Cataract Refract Surg. 2006;32:1907-1912.
Clinical Ophthalmology

\section{Publish your work in this journal}

Clinical Ophthalmology is an international, peer-reviewed journal covering all subspecialties within ophthalmology. Key topics include: Optometry; Visual science; Pharmacology and drug therapy in eye diseases; Basic Sciences; Primary and Secondary eye care; Patien Safety and Quality of Care Improvements. This journal is indexed on

\section{Dovepress}

PubMed Central and CAS, and is the official journal of The Society of Clinical Ophthalmology (SCO). The manuscript management system is completely online and includes a very quick and fair peer-review system, which is all easy to use. Visit http://www.dovepress.com/ testimonials.php to read real quotes from published authors. 